\title{
MENIERE'S DISEASE
}

\author{
Helena Era Millennie ${ }^{1}$, Badrul Munir ${ }^{2}$, Zamroni Afif ${ }^{2}$, Ria Damayanti², Shahdevi Nandar Kurniawan ${ }^{2}$ \\ ${ }^{1}$ Doctor Profession Study Program, Medical Faculty, Brawijaya University, Saiful Anwar General Hospital, Malang, Indonesia. \\ ${ }^{2}$ Neurology Department, Medical Faculty, Brawijaya University, Saiful Anwar General Hospital, Malang, Indonesia.
}

Correspondence : shahdevinandar@ub.ac.id

\begin{abstract}
Meniere's disease is a disorder of the inner ear resulting in symptoms of episodic vertigo, tinnitus, hearing loss and aural pressure. Although the exact etiology is uncertain, it is associated with raised pressure in the endolymph of the inner ear (endolymphatic hydrops). The diagnosis of Meniere's disease is based on the clinical setting of the patient. This disease usually presents with unilateral ear symptoms but can be also bilateral. Meniere's disease attacks are usually random and episodic (approximately 6-11 per year), with periods of remission that can last from months to years. Investigations are audiometry, electronystagmogram, vestibular evoked myogenic potentials (VEMPs) and imaging.The management consist pharmacological and non pharmacological. Meniere's disease is initially progressive but fluctuates unexpectedly. It is difficult to distinguish natural resolutions from treatment effects.
\end{abstract}

Keyword : Meniere's disease, episodic vertigo, tinnitus, hearing loss and aural pressure.

\section{INTRODUCTION}

Meniere's disease is characterized by spontaneous attacks of vertigo, fluctuating sensorineural hearing loss, aural pressure, and tinnitus. Meniere's disease is one of the clinically significant diseases because it has serious implications for the affected person. Unanticipated attacks that keep repeating will disrupt the patient's daily life, it can even bother the patient's professional career (1).

\section{DEFINITION}

Meniere's disease is a disorder of the inner ear that results in symptoms of episodic vertigo, tinnitus, hearing loss, and aural pressure (2). Clinically, fluctuating sensorineural hearing loss tends to be resistant to treatment (progressive), but the symptoms of episodic vertigo are usually quite responsive to treatment (3).

\section{EPIDEMIOLOGY}

Meniere's disease occurs approximately 50 to 200 per 100,000 adults and is most common in between 40 and 60 years old. Several studies have suggested that the prevalence of Meniere's disease is slightly higher in women than in men, with a reported female: male ratio in the United States of 1.89: 1.30. Becker-Bense et al. hypothesized that the main cause of this female predominance was because there was a mixture of patients who had vestibular migraine which the symptoms is similar with Meniere's disease. In some Meniere's disease patients, the symptoms of decreased hearing function are the most significant symptoms in the first decade of diagnosis, however the patient continues to experience a deterioration that makes this a chronic disease $(4,5)$.

\section{ETIOLOGY}

\section{Genetic}

Several lines of epidemiological evidence support a genetic contribution in Meniere's disease, including (a) the higher prevalence observed in the European population over other ethnicities and (b) a strong familial aggregation found in Europeans and South Koreans.

Two genes for the immune response have been associated with the development of hearing loss in Meniere's disease. In a separate study, the common variant rs11096955 in the TLR10 gene also influenced the development of sensorineural hearing loss in patients with bilateral Meniere's disease. The MIF gene mediates the production of proinflammatory cytokines and increases autoimmune-mediated nerve inflammation.

Additional evidence for genetic contribution is also supported by a study conducted in four families with Meniere's disease with an autoimmune background.

\section{Autoimmune}

The autoimmune mechanism involved in this disease is still uncertain. There are several hypotheses have been proposed to explain the development of autoimmune responses in the inner ear: (a) a cross-reaction due to shared epitopes between inner ear proteins and microbial proteins, such as cochlin,

\section{Article History:}

Received: January 25, 2021; Accepted: February 17, 2021; Published: March 1, 2021

\section{Cite As:}

Millennie HE, Munir B, Afif Z, Damayanti R, Kurniawan SN. Meniere's disease. Journal of Pain, Vertigo and Headache; 2021.1:18-21 
(b) collateral damage due to persistent levels of cytokines and chemokines that can trigger the reaction delayed immunity, possibly explaining the relapsing / remitting course of Meniere's disease, (c) intolerance to inner ear antigens, and (d) immunogenetic factors leading to a persistent inflammatory.

\section{PATHOPHYSIOLOGY}

Attacks of episodic vertigo can be explained by two theories. The first is the rupture theory which states that an increase in pressure within the scala media results in the rupture of Reissner's membrane. Endolymph and perilymph will come together which in turn causes vertigo attacks. This theory is based on historical histological specimens of individuals with Meniere's disease (2).

The second theory is the drainage theory. Drainage theory suggests that excess endolymph at the scala media will eventually flow rapidly from the cochlear duct, saccule and into the endolymphatic sinus. Once the capacity of the endolymphatic sinus is reached, the valve that separates the utricle and sinus is breached and the endolymph overflows into the utricle, stretching the crest of the semicircular canal causing vertigo (2). Furthermore, if there is blockage of the endolymphatic duct or Bast valve which is responsible for the drainage function, it can cause endolymphatic hydrops. Endolymphatic hydrops can also result from overproduction of endolymph (7) which can make a damage to the organs of the corti (6).

\section{CLINICAL MANIFESTATIONS}

Symptoms of Meniere's disease are episodic vertigo, tinnitus, hearing loss, and aural pressure. The vertigo is typically rotatory, makes the patient feeling weak and may be accompanied by nausea, vomiting and the less common symptom is diarrhea. Vertigo usually lasts more than 20 minutes but rarely exceeds four hours and rarely has more than one attack within 24 hours. Between attacks, the balance function subjectively returns to normal. Hearing loss, tinnitus symptoms and aural pressure are fluctuating. There are three stages in Meniere's disease:

\section{Stage one}

Dominant symptom in the stage one is the attack of vertigo and usually occurs with severe intensity. Hearing levels fluctuate, but recover to normal levels between attacks. Tinnitus and aural pressure often improve or disappear between attacks, with hearing function and balance tests often normal.

\section{Stage two}

There continues to be repeated episodes of vertigo. Hearing may still fluctuate but not fully recover to normal levels. Tinnitus and aural pressure usually don't completely dissapear between attacks.

\section{Stage three}

The patient may also experience a Tumarkin drop attack, in where the patient suddenly falls without warning, without loss of consciousness and without neurological symptoms but this is rare. Hearing level remains poor (threshold around 60
$\mathrm{dBHL})$. Usually, there is tinnitus and a persistent sensation of aural pressure $(2,8)$.

\section{DIAGNOSIS}

A strict clinical classification for the diagnosis of Meniere's disease has been established by the American Academy of Otolaryngology- Head and Neck Surgery (AAO-HNS). The diagnostic criteria for Meniere's disease has been revised by the Classification Committee of the Barany Society and resulted in 2 categories: Definitive Meniere's disease; two or more spontaneous vertigo attacks, each lasting 20 minutes to 12 hours, audiometric examination reveals low-to-moderate frequency fluctuation of sensorineural hearing loss in the affected ear at least 1 time before, during, or after one vertigo episode, fluctuating aural symptoms (hearing loss, tinnitus, or aural pressure) in the affected ear, other causes excluded by other tests. Possible Meniere's Disease; at least 2 episodes of vertigo or dizziness lasting 20 minutes to 24 hours, fluctuating aural symptoms (hearing loss, tinnitus, or aural pressure) in the affected ear, other causes excluded by other tests $(4,6,9-11)$.

The diagnosis of Meniere's disease was made clinically. This disease usually presents with unilateral ear symptoms but can be also bilateral. Meniere's disease attacks are usually random and episodic (approximately 6-11 per year), with periods of remission that can last from months to years. Thus, the diagnosis of Meniere's disease is usually not made at 1 point in time, it may take months or even years to fully lead to a definitive diagnosis. To maximize treatment, it is important to differentiate Meniere's disease from other independent causes of vertigo and present with hearing loss, tinnitus, for example, BPPV, acute labyrinthitis, migraine which are responding to different treatments $(4,12)$. Furthermore, there is a tool to make a diagnosis, the Gibson 10 point score, where a score of 7 or more leads to a diagnosis of Meniere's disease (2).

Table 1. Gibson 10 point score (2)

\begin{tabular}{lc}
\hline Gibson 10 point score & Score \\
\hline Vertigo & 1 \\
\hline Rotational vertigo & 1 \\
$\begin{array}{l}\text { Duration of rotational vertigo }>10 \text { minutes } \\
\text { Rotational vertigo associated with at least one symptom }\end{array}$ & 1 \\
: hearing loss, tinnitus, or aural pressure & \\
\hline Hearing loss & 1 \\
\hline Sensorineural hearing loss & 1 \\
Fuctuating hearing loss & 1 \\
Hearing loss or fluctuation associated with at least one & 1 \\
symptom : vertigo, tinnitus, or aural pressure & 1 \\
\hline Tinnitus & \\
\hline $\begin{array}{l}\text { Duration of tinnitus }>5 \text { minutes } \\
\text { Fluctuative tinnitus associated with at least one }\end{array}$ & 1 \\
\hline symptom : vertigo, hearing loss, or aural pressure & 1 \\
\hline Aural Pressure & \\
\hline $\begin{array}{l}\text { Fluctuative aural pressure associated with at least one } \\
\text { symptom : vertigo, hearing loss, or tinnitus }\end{array}$ & \\
\hline
\end{tabular}

\section{INVESTIGATIONS}

\section{Audiometry}

Audiometry is important to determine the hearing threshold and monitor any fluctuation. Early hearing losses often affects the lower frequencies, which suggests that 
endolymphatic hydrops initially affects the apex of the cochlea2. This examination can occur for 30 minutes (4).

\section{Video- or electronystagmogram}

This examination is used to evaluate the vestibulo-ocular reflex. This examination is performed in a dark room while eye's movement is recorded as warm or cold water or air is added to each canalis acusticus externus. This examination can trigger vertigo and nausea and it can occur for one hour (4).

\section{Vestibular evoked myogenic potentials (VEMPs)}

The role of vestibular evoked myogenic potentials (VEMPs) in the diagnosis of Meniere's disease is currently uncertain. However, there is some evidence that might support its use as an objective test. Reflexes that occur in response are obtained through the sternocleidomastoid and orbital muscles due to strong acoustic stimulation. This can be used as bone conduction or air conduction to stimulate the otolith. Currently VEMP is more widely used to monitor muscle function and the effect of intratimpanic gentamicin (13).

\section{Imaging}

Magnetic resonance imaging (MRI) of the inner ear after intratimpanic gadolinium injection may be performed for evaluation of visualization of endolymphatic hydrops. Gadolinium will be perfused through the membrana tympani secundaria or membrana fenestrae cochleae or round window membrane that allowing the examiner to distinguish the boundary between the endolymphatic space and the perilymphatic space. A delay of 4 hours is required after dual dose gadolinium injection. Both ears can be assessed but there is a risk of systemic toxicity due to the use of high doses of gadolinium. On the MRI results, if the endolymphatic duct is expanded by more than $33 \%$, this can be said to be endolymphatic hydrops. However, visualization of endolymphatic hydrops is not required to determine Meniere's disease and MRI imaging should not be used to replace the diagnostic criteria for Meniere's disease if all defined criteria are fulfilled (13).

\section{DIFFERENTIAL DIAGNOSIS}

Before making a diagnosis of Meniere's disease, other conditions must be excluded which can be seen in the Table 2.

\section{MANAGEMENT}

\section{Non Pharmacological}

\section{Diet and lifestyle modification}

A low-sodium diet (1500-2300 mg / day) and high water intake can prevent vasopressin release and help maintain inner ear homeostasis. The AAO-HNS suggests caffeine restriction because caffeine can induce endolymph volume modification. Some assume that a low amount of caffeine, such as $100 \mathrm{mg} /$ day, will not trigger Meniere's symptoms $(4,13)$. Patients are also advised to avoid alcohol and tobacco. In addition, stress is a known factor contributing to Meniere's attacks, so things need to be done to reduce stress (2).

\section{Vestibular rehabilitation}

Vestibular rehabilitation is exercise and physical maneuvers to treat chronic balance disorders (4).
Table 2. Differential Diagnosis of Meniere's Disease (4)

\begin{tabular}{|c|c|c|}
\hline Condition & Clinical Manifestation & $\begin{array}{l}\text { Differentiation from } \\
\text { Meniesre's Disease }\end{array}$ \\
\hline $\begin{array}{l}\text { Benign } \\
\text { paroxysmal } \\
\text { positional } \\
\text { vertigo }\end{array}$ & $\begin{array}{l}\text { Vertigo due to a change } \\
\text { in head position that } \\
\text { lasts less than } 1 \text { minute }\end{array}$ & $\begin{array}{l}\text { It is not accompanied with } \\
\text { hearing loss, tinnitus, or } \\
\text { aural } \\
\text { fullness. Vertigo occurs in } \\
\text { short duration }\end{array}$ \\
\hline $\begin{array}{l}\text { Stroke/ } \\
\text { ischemia }\end{array}$ & $\begin{array}{l}\text { Vertigo lasting in a few } \\
\text { minutes with other } \\
\text { symptoms: nausea, } \\
\text { vomiting, imbalance, } \\
\text { and also visual blurring } \\
\text { and drop attacks }\end{array}$ & $\begin{array}{l}\text { The symptoms are often } \\
\text { permanent and do not } \\
\text { fluctuate, comorbid with } \\
\text { dysphagia, dysphonia, or } \\
\text { other neurologic symptoms } \\
\text { and signs, usually not } \\
\text { accompanied with hearing } \\
\text { loss and tinnitus }\end{array}$ \\
\hline $\begin{array}{l}\text { Vestibular } \\
\text { migraine }\end{array}$ & $\begin{array}{l}\text { The attack lasting for } \\
\text { hours but can also } \\
\text { lasting for minutes or } \\
>24 \text { hours }\end{array}$ & $\begin{array}{l}\text { Duration of attacks may be } \\
\text { shorter or longer than } \\
\text { Meniere's disease. Hearing } \\
\text { loss less likely. Patients } \\
\text { often have a migraine history }\end{array}$ \\
\hline $\begin{array}{l}\text { Vestibular } \\
\text { schannoma }\end{array}$ & $\begin{array}{c}\text { The symptoms of } \\
\text { vestibular schannoma } \\
\text { such as chronic } \\
\text { imbalance, asymmetric } \\
\text { hearing loss and } \\
\text { tinnitus. Vertigo can } \\
\text { also occurs in this } \\
\text { disease }\end{array}$ & $\begin{array}{l}\text { Chronic imbalance more } \\
\text { likely than profound episodic } \\
\text { Vertigo. Hearing loss does } \\
\text { not typically fluctuate. }\end{array}$ \\
\hline Labyrinthitis & $\begin{array}{c}\text { Sudden severe vertigo } \\
(>24 \text { hours }) \text { with } \\
\text { hearing loss } \\
\end{array}$ & $\begin{array}{c}\text { Vertigo, nausea with hearing } \\
\text { loss but it doesn't occur } \\
\text { episodic and fluctuating }\end{array}$ \\
\hline $\begin{array}{l}\text { Vestibular } \\
\text { neuritis }\end{array}$ & $\begin{array}{l}\text { Acute vertigo that have } \\
\text { a long duration of } \\
\text { attack, can be } \\
\text { associated with nausea, } \\
\text { vomiting, without } \\
\text { hearing loss, tinnitus, } \\
\text { and aural fullness }\end{array}$ & $\begin{array}{l}\text { Vertigo, nausea without } \\
\text { hearing loss }\end{array}$ \\
\hline
\end{tabular}

\section{Pharmacological}

The role of pharmacological agents is to reduce the frequency of vertigo attacks and reduce the associated ear symptoms:

\section{Betahistine}

Betahistine dihydrochloride is an oral drug that has been used for the treatment of peripheral vertigo. This drug is a histamine analogue that is highly histamine $\mathrm{H} 3$ receptor antagonist and acts as a weak agonist at histamine $\mathrm{H} 1$ receptors4. Betahistine is considered to prevent symptoms due to its vasodilating effect on the inner ear. Based on clinical experience, the use of Betahistine $48 \mathrm{mg}$ for 3-6 months to prevent Meniere's attack can be recommended (13).

\section{Diuretic}

Diuretics are generally given as first-line therapy for Meniere's disease (13). Diuretics are believed to alter the electrolyte balance in the endolymph, thereby decreasing the endolymph volume. The most commonly prescribed diuretics are thiazides with or without potassium-sparing diuretics such as triamterene. The second line is the carbonic anhydrase inhibitor such as acetazolamide. Contraindications to the use of thiazides are patients with gout and potassium-sparing diuretics are contraindicated in patients with acute or severe renal failure. Patients using diuretics should be monitored for electrolytes and blood pressure (4). 


\section{Corticosteroids}

The mechanism of action of intratympanic steroid therapy is to stabilize the vascular endothelium and increase cochlear blood flow through anti-inflammatory effects, as well as effects on cochlear ion and fluid homeostasis. Methylprednisolone and dexamethasone are commonly corticosteroids that are usually prescribed. Methylprednisolone penetrates the round window more easily and achieves a higher concentration in the endolymph after intratympanic injection than dexamethasone. However, dexamethasone is more rapidly absorbed into the inner ear stria and surrounding tissues than methylprednisolone. The dose is $0.4-0.8 \mathrm{~mL}$ injected into the middle ear space, from once or up to 3 to 4 sessions every 3 to 7 days depending on clinical response (4).

\section{Gentamicin}

The effect of gentamicin is atrophy in vestibular type 1 cells and neuroepithelium. The recommended application of gentamicin is a one-time injection with a concentration of $26.7 \mathrm{mg} / \mathrm{Ml}$ (13).

\section{Operative}

A small number of patients will fail to respond to the both pharmacological and non-pharmacological management or may suffer a Tumarkin drop attack, the patients are suggested to do labyrinthectomy or vestibular nerve section for vertigo control (2).

\section{Labyrinthectomy}

The goal of this therapy is to remove abnormal elements of the sensory neuroepithelium in the semicircular canals and otoliths that are believed to cause episodes of vertigo in patients with Meniere's disease (4).

\section{Vestibular nerve section}

This therapy is an intradural procedure that involves selective transection of the vestibular nerve but the cochlear nerve is preserved (4).

\section{PROGNOSIS}

Meniere's disease is initially progressive but fluctuates unexpectedly. It is difficult to distinguish natural resolutions from treatment effects. Acute vertigo attacks often increase in frequency during the first few years and then decrease in frequency in association with continued hearing loss. In most people, episodes of vertigo eventually stop completely. In one 20 -year cohort study of 34 people, $28(82 \%)$ had at least moderate to severe hearing loss (mean pure tone hearing loss $>50 \mathrm{~dB}$ ) and $16(47 \%)$ developed bilateral disease. Symptoms other than hearing loss improve in $60 \%-80 \%$ of people irrespective of treatment (12).

\section{CONCLUSION}

Meniere's disease is a disorder of the inner ear that causes symptoms of episodic vertigo, tinnitus, hearing loss, and aural pressure. The diagnosis of Meniere's disease is based on the clinical setting of the patient. Management that can be given is in the form of non-pharmacological therapy (dietary and life style modifications), pharmacology (betahistine, diuretics, gentamicin and corticosterioids), as well as operative if it fails on non-pharmacological therapy and pharmacological therapy.

\section{ACKNOWLEDGMENT}

None.

\section{CONFLICT OF INTEREST}

The authors declare that there is no conflict of interest.

\section{REFERENCES}

1. Buki B, Tarnutzer AA. Vertigo and Dizziness. First edit. Oxfort University Press; 2014.

2. Kanegaonkar RG, Tysome JR. Dizziness and Vertigo : An Introduction and Practical Guide; 2014.

3. Rauch SD. Ménière's disease: damaged hearing but reduced vertigo. Lancet; 2016. 388(10061):2716-2717. DO1: 10.1016/S0140-6736(16)32166-3

4. Basura GJ, Adams ME, Monfared A, et al. Clinical practice guideline: Ménière's disease executive summary. Otolaryngol - Head Neck Surg (United States); 2020. 162(4):415-434

DOI: $10.1177 / 0194599820909439$

5. Becker-Bense S, Wittmann C, Dieterich M. Balanced sex distribution in patients with Menière's disease. J Neurol; 2019. 266(1):42-46. DOI: 10.1007/s00415-01909301-4

6. Lopez-Escamez JA, Batuecas-Caletrio A, Bisdorff A. Towards personalized medicine in Ménière's disease. F1000Research; 2018. 7(0):1-9.

DOI: $10.12688 /$ f1000research.14417.1

7. Cureoglu S, Monsanto R da C, Paparella MM. Histopathology of Meniere's disease. Oper Tech Otolayngol Head Neck Surg; 2016. 27(4):194-204. DOI: 10.1016/j.otot.2016.10.003.Histopathology

8. Gürkov R, Pyykö I, Zou J, Kentala E. What is Menière's disease? A contemporary re-evaluation of endolymphatic hydrops. J Neurol; 2016. 263:71-81. DOI: 10.1007/s00415-015-7930-1

9. Wang Y, Diao T, Han L, Tao Y, Yu L. Association of Meniere's disease and retinal vascular calibre: A prospective observational study in China. BMJ Open; 2018. 8(10). DOI: 10.1136/bmjopen-2018-022069

10. Tabet P, Saliba I. Meniere's disease and vestibular migraine: Updates and review of the literature. J Clin Med Res; 2017. 9(9):733-744.

DOI: $10.14740 /$ jocmr3126w

11. Van Esch BF, Van Benthem PPG, Van Der ZaagLoonen HJ, Bruintjes TJD. Age of onset of Ménière's disease in the Netherlands: Data from a specialised dizziness clinic. J Laryngol Otol; 2016. 130(7):624-627. DOI: $10.1017 / \mathrm{S} 0022215116007982$

12. Wright T. Menière's disease. Ear, Nose, Throat Disord; 2015. 11(505):1-18.

13. Magnan J, Özgirgin ON, Trabalzini F, et al. European position statement on diagnosis, and treatment of meniere's disease. J Int Adv Otol; 2018. 14(2):317-321. DOI: $10.5152 /$ iao.2018.140818 